\title{
Emerging Treatments for Advanced/Metastatic Pheochromocytoma and Paraganglioma
}

Maran Ilanchezhian, $B S^{1}$

Abhishek Jha, $M D^{2}$

Karel Pacak, MD, PhD, DSC ${ }^{2}$

Jaydira Del Rivero, $M D^{3,4, *}$

\author{
Address \\ ${ }^{1}$ Pediatric Oncology Branch, Center for Cancer Research, National Cancer Institute, \\ Bethesda, MD, USA \\ ${ }^{2}$ Eunice Kennedy Shriver National Institute of Child Health and Human Develop- \\ ment, National Institutes of Health, Bethesda, MD, USA \\ ${ }^{*}, 3$ Developmental Therapeutics Branch, Rare Tumor Initiative, Center for Cancer \\ Research, National Cancer Institute, Bethesda, MD, USA \\ Email: jaydira.delrivero@nih.gov \\ ${ }^{4}$ Medical Oncology \& Clinical Endocrinology, Center for Cancer Research, National \\ Cancer Institute/National Institutes of Health, 10 Center Drive, MSC 1906, Build- \\ ing 10, CRC 13C-434, Bethesda, MD, 20892, USA
}

Published online: 29 August 2020

(C) The Author(s) 2020

This article is part of the Topical Collection on Neuroendocrine Cancers

Keywords Pheochromocytoma · Paraganglioma · Genetics · Imaging · Oncogenic signaling · Therapy

\section{Opinion statement}

The incidence of metastatic pheochromocytoma (PHEO) and paraganglioma (PGL) may occur in as many as $35 \%$ of patients particularly with PGL and even more frequently in those with specific mutations. Biochemical, morphological, and molecular markers have been investigated for use in the distinction of benign from malignant PHEO/PGL. PHE0/PGL metastasizes via hematogenous or lymphatic routes and shows differences based on mutational status. The most common sites of involvement in patients that have an SDHB mutation are the bone (78\%), lungs ( $45 \%)$, lymph nodes $(36 \%)$, and liver $(35 \%)$. In patients with sporadic PHEO/PGL, the most common sites of metastasis are the bones $(64 \%)$, lungs $(47 \%)$, lymph nodes $(36 \%)$, and liver $(32 \%)$. Metastases may be present at presentation or may occur later. Metastases to the liver and lungs are associated with a shorter survival. Overall, the estimated 5 -year survival rates are between 34 and $74 \%$. Currently, treatments for metastatic PHEO/PGL are essentially palliative. Surgery is potentially curative; however, tumor dissemination limits the chance for a curative resection. 
When surgical intervention is not amenable, the therapeutic options include radiolabeled MIBG (Azedra ${ }^{\circledR}$-iobenguane 131 was recently FDA-approved for patients $>12$ years and older with iobenguane scan positive) or systemic chemotherapy with cyclophosphamide, vincristine, and dacarbazine (CVD) with an overall objective response rate (ORR) of less than $40 \%$; however, it is not clear if the administration of CVD impacts overall survival, as nearly all patients develop progressive and ultimately fatal disease. Other treatment modalities under investigation include cytoreductive techniques, novel radiopharmaceuticals, chemotherapy, radiotherapy, immunotherapy, and experimental therapies. Here we are discussing emerging treatment for advanced/metastatic PHEO/PGL.

\section{Introduction}

Pheochromocytomas (PHEOs) and paragangliomas (PGLs) are rare neuroendocrine tumors that arise from chromaffin cells. PHEOs arise from the adrenal medulla, while PGLs arise from the neural crest progenitors located outside of the adrenal gland [1]. The incidence of PHEO/PGL is estimated to be around 1 per 300,000 people, with an average diagnosis age of $40[2,3]$. The clinical presentation of PHEO/PGL is variable and overlaps with similar symptoms occurring in other disease conditions. Most of the symptoms of PHEO/PGL are an effect of the overproduction of catecholamines [4]. These include hypertension, headache, palpitations, and anxiety. Hypertension is the most common presenting symptom and can be paroxysmal or sustained. Some patients may present with orthostatic hypotension [5]. Sympathetic PHEO/PGLs frequently produce considerable amounts of catecholamines and are found in the adrenal medulla in $80 \%$ of patients $[1,6]$. There are no curative treatments for metastatic PHEO/PGL and current systemic therapies are accompanied with side effects that can interfere with the quality of life. In patients with metastatic PHEO/PGL with no evidence of disease progression and asymptomatic, active surveillance is appropriate $[7,8]$. If evidence of disease progression and symptomatic, multiple lines of treatment are considered, including hormonal symptoms control, surgery of the primary tumor and/or metastases, ablation/ embolization, radiotherapy, and systemic therapies [7, $9,10]$ in metastatic PHEO/PGL. Moreover, excessive hormone production (epinephrine and/or norepinephrine) is complicated with cardiovascular disease and gastrointestinal dysfunction $[11,12]$.

\section{Genetics}

The majority of PHEOs/PGLs are sporadic tumors and of these, $25-30 \%$ are associated with somatic mutations [13]. About 35\% are familial in origin where patients are found to harbor germline mutations in over 20 susceptibility genes $[14,15]$. The mutations associated with PHEO/PGL can be grouped into 3 clinically relevant clusters: pseudohypoxia, kinase signaling, and Wnt signaling $[16 \bullet, 17 \bullet \bullet]$. The pseudohypoxia group (cluster I) contains mutations in SDHA, SDHB, SDHC, SDHD, SDHAF2, FH, VHL IDH1/2, MHD2, PHD1/2, and HIF2/

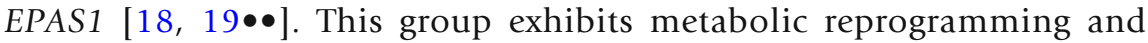
pseudohypoxic signaling that are hallmarks of the aforementioned mutations [20]. The kinase signaling group (cluster II) consists of mutations in RET, NF1, TMEM127, MAX, and HRAS [16•]. The Wnt signaling group (cluster III) includes CSDE1 and MAML3 gene mutations. Patients with mutations in this group exclusively present as somatic mutations and it has been proposed that 


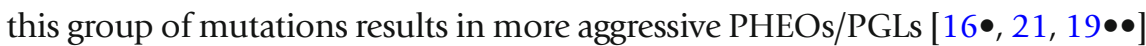
(Fig. 1).

Succinate dehydrogenase $(S D H)$ mutations are found in approximately $27 \%$ of patients with advanced PHEO/PGL [22]. Astuti et al. first described in 2001 that mutations in succinate dehydrogenase subunit B (SDHB) have been linked to more aggressive tumor behavior, demonstrated as a higher rate of

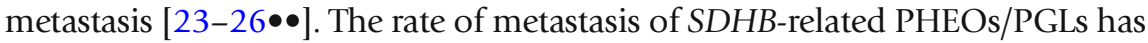
been reported to be between 34\% [22] and 71\% [27], with a 5-year survival rate of $36 \%$ after the diagnosis of metastasis [28]. The metastatic potential attributed to mutations in the other SDH subunits has been described as 21\% in SDHA, rarely malignant in SDHC, and $<10 \%$ in SDHD [29].

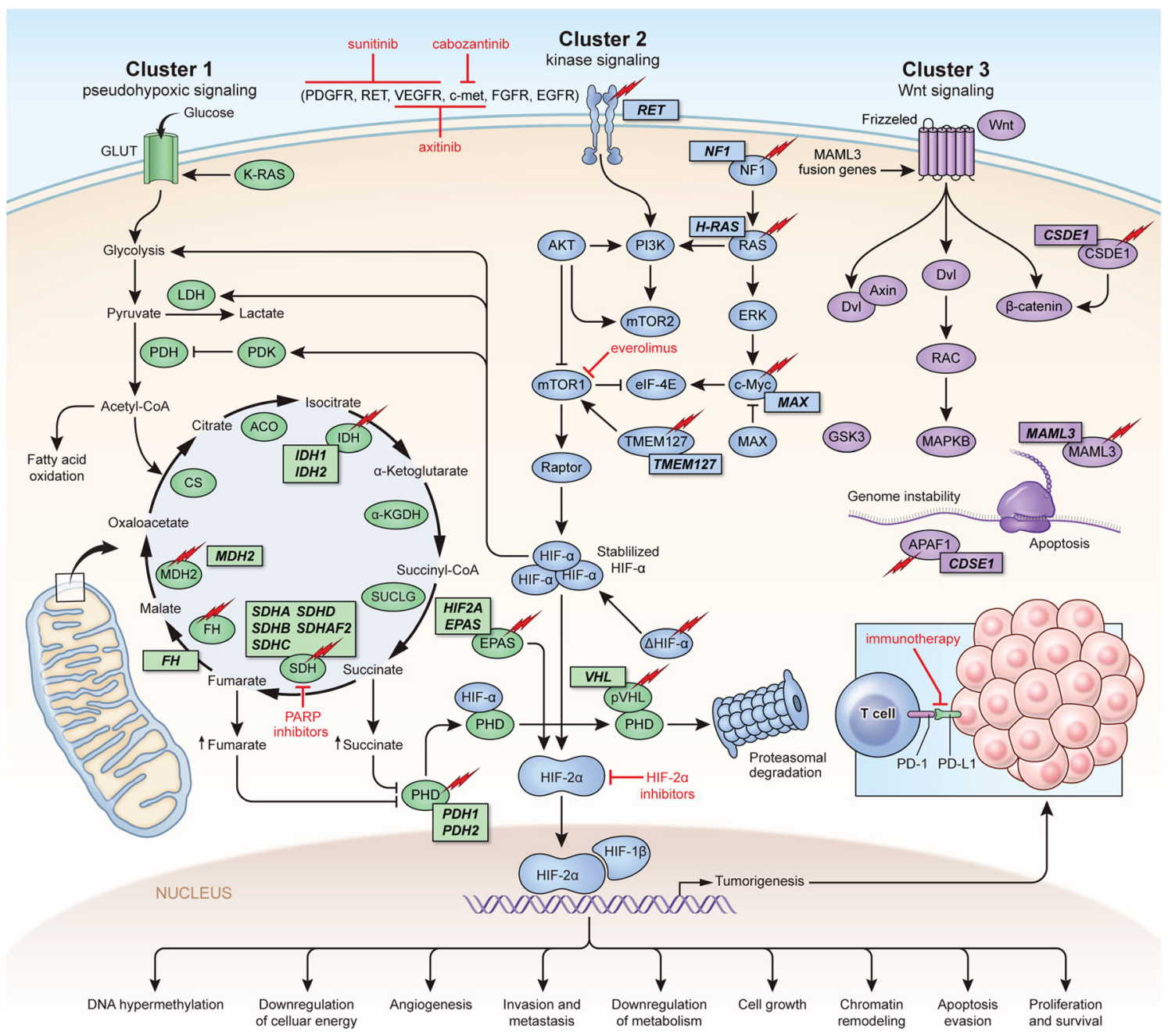

Fig. 1. Genetics and molecular pathways for pheochromocytoma and paragangliomas. Clusters I, II, and III with molecular-targeted options. Cluster I PHEOs/PGLs, also known as the pseudohypoxia group, are characterized by mutations in SDHA, SDHB, SDHC, SDHD, SDHAF2, FH, VHL, and EPAS1 [20]. Cluster II PHEOs/PGLs, also known as the kinase signaling group, are characterized by mutations in RET, NF1, TMEM127, MAX, and HRAS [16]. The Wnt signaling group (cluster III) includes mutations in the genes CSDE1 and MAM $[73,74]$. 


\section{Diagnosis of PHE0/PGL}

The diagnosis of PHEO and PGL is based on the presence of symptoms, biochemical confirmation, and different imaging modalities. Biochemical testing is based on the continuous production of catecholamines and their metabolites are called metanephrines [6,30]. Imaging procedures include anatomical and functional techniques [31, 32]. Ga-68 DOTATATE and other diverse radionuclide imaging techniques are available for the diagnosis, staging, and followup of PHEO/PGL and an attempt has further been made to characterize the radionuclide of choice across the genotypes [31, 32] (Fig. 2).

\section{Management of advanced disease}

The frequency of metastatic PHEOs/PGLs in certain genetic disorders ranges from 1 to $90 \%$. SDH mutations are found in approximately 30\% of patients with metastatic PHEO/PGL [33]. SDHB mutations have been linked to more aggressive tumor behavior, and are more likely to present with metastatic disease than patients with sporadic PHEOs/PGLs [23-25]. Eisenhofer et al. have described an increase in the likelihood of metastases in PHEOs from less than $6 \%$ for tumors smaller than $5 \mathrm{~cm}$ to over $50 \%$ in tumors larger than $10 \mathrm{~cm}$; for PGLs, the rate of malignancy increases to over $80 \%$ for tumors larger than $9 \mathrm{~cm}$ [34].

SDHB-related PHEO/PGL, extra-adrenal location, younger age at initial presentation, larger size of the primary tumor, and elevated norepinephrine, dopamine, and its metabolite methoxytyramine levels have been explored as risk factors for the metastatic behavior of PHEOs/PGLs [23, 35-38]. While histopathological characteristics of tumors may not show a definite diagnosis of malignancy, clinical correlates, such as a tumor weight $>80 \mathrm{~g}$, high tumor concentration of dopamine, tumor size $>5 \mathrm{~cm}$, presence of confluent tumor
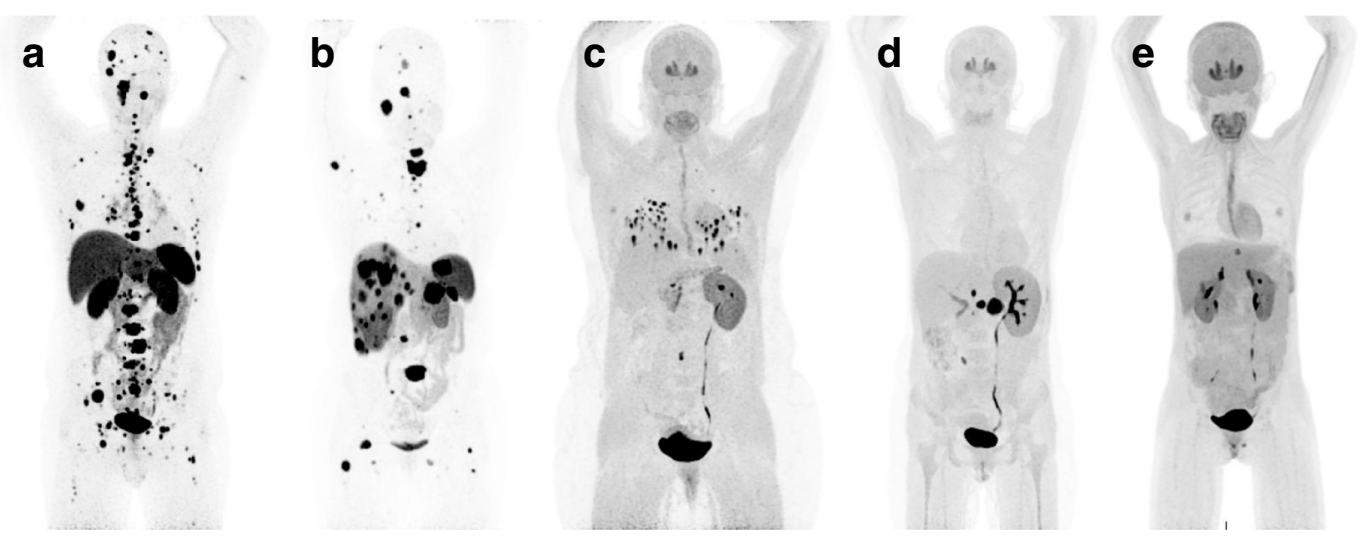

Fig. 2. This figure demonstrates the preferred radionuclide to be used in various cohorts of pheochromocytoma (PHE0) and/or paraganglioma (PGL) per latest joint guidelines proposed by European Association of Nuclear Medicine and Society of Nuclear Medicine and Molecular Imaging. The preferred radionuclide in metastatic SDHB-related PHEO/PGL (a) and metastatic sporadicPHE0/PGL (b) is ${ }^{68} \mathrm{Ga}$-DOTATATE. However, ${ }^{18} \mathrm{~F}$-FDOPA is the radionuclide of choice in metastatic VHL- (c), HIF2A- (d), and RET- (e) mutated patients. 
necrosis, extra-adrenal tumor location, adrenal PHEO that does not take up metaiodobenzylguanidine (iobenguane, MIBG), and a younger age, have been associated with an increased likelihood for metastatic behavior [39].

At present, most treatments for metastatic PHEOs/PGLs are palliative. Surgery is potentially curative; however, tumor dissemination limits the chance for a curative resection [40]. Other treatment modalities include cytoreductive techniques, radiopharmaceuticals, chemotherapy, radiotherapy, and experimental therapies. Targeted radiotherapy using ${ }^{131}$ I MIBG (Azedra ${ }^{\circledR}$ ) is an option in systemic treatment. Radiolabeled somatostatin analogues are being investigated $[41,42]$. Less than $40 \%$ of patients with metastatic PHEO respond (usually partial rather than complete response) to currently used therapeutic modalities such as ${ }^{131}$ I MIBG or chemotherapy [43] (Fig. 3).

\section{Pseudohypoxia group (cluster I) targeted therapies}

Cluster I PHEOs/PGLs, also known as the pseudohypoxia group, are characterized by mutations in SDHA, SDHB, SDHC, SDHD, SDHAF2, FH, VHL, and EPAS1 [20].

Antiangiogenic therapy

PHEOs/PGLs are highly vascularized tumors, which support the notion that anti-angiogenic therapies may be options for treatment [44, 45]. Vascular endothelial growth factor (VEGF), a well characterized angiogenic factor, has been shown to be upregulated in metastatic PHEO, which suggests that it could be a potential therapeutic target [46]. Currently, human VEGF-A monoclonal antibodies and tyrosine kinase inhibitors are used as angiogenic therapies. These therapies have already been approved for patients with advanced cell renal carcinoma, including patients with $S D H B$ mutations. Several case reports have also shown a partial response or stable disease in cluster I PHEOs/PGLs treated with tyrosine kinase inhibitors [47-50]. Ongoing trials are being conducted to explore the efficacy of tyrosine kinase inhibitors in advanced/ metastatic PHEO/PGL (Table 1). Two phase II trials are currently under way to study the response of patients with metastatic PHEO/PGL to sunitinib. One of these trials (NCT00843037) has shown a disease control rate of 83\% (3/25 patients achieved a partial response and $16 / 25$ patients had stable disease). All patients who responded were carriers of germline mutations in the cluster I genes, SDHA, SDHB, or in RET [51]. In addition, two phase II trials for the tyrosine kinase inhibitor axitinib are also under way. Preliminary results from the NCT01967576 phase II trial of axitinib have shown partial responses in 3/9 patients as well as stable disease in 5 additional patients [52]. Phase II trials studying VEGF inhibitors, lenvatinib and dovitinib, are also in progress and both are enrolling patients with PHEO/PGL (Table 1, Fig. 1).

\section{Hypoxia-inducible factor (HIF) inhibitors}

Abnormal activation of hypoxia signaling is another one of the characteristics of cluster I PHEOs/PGLs [53]. As a result, HIF inhibitors could be a potential therapy for patients with cluster I PHEO/PGL. Molecular studies have identified HIF- $2 \alpha$ as one of the main oncogenic drivers of PHEOs/PGLs [44, 54-56]. 


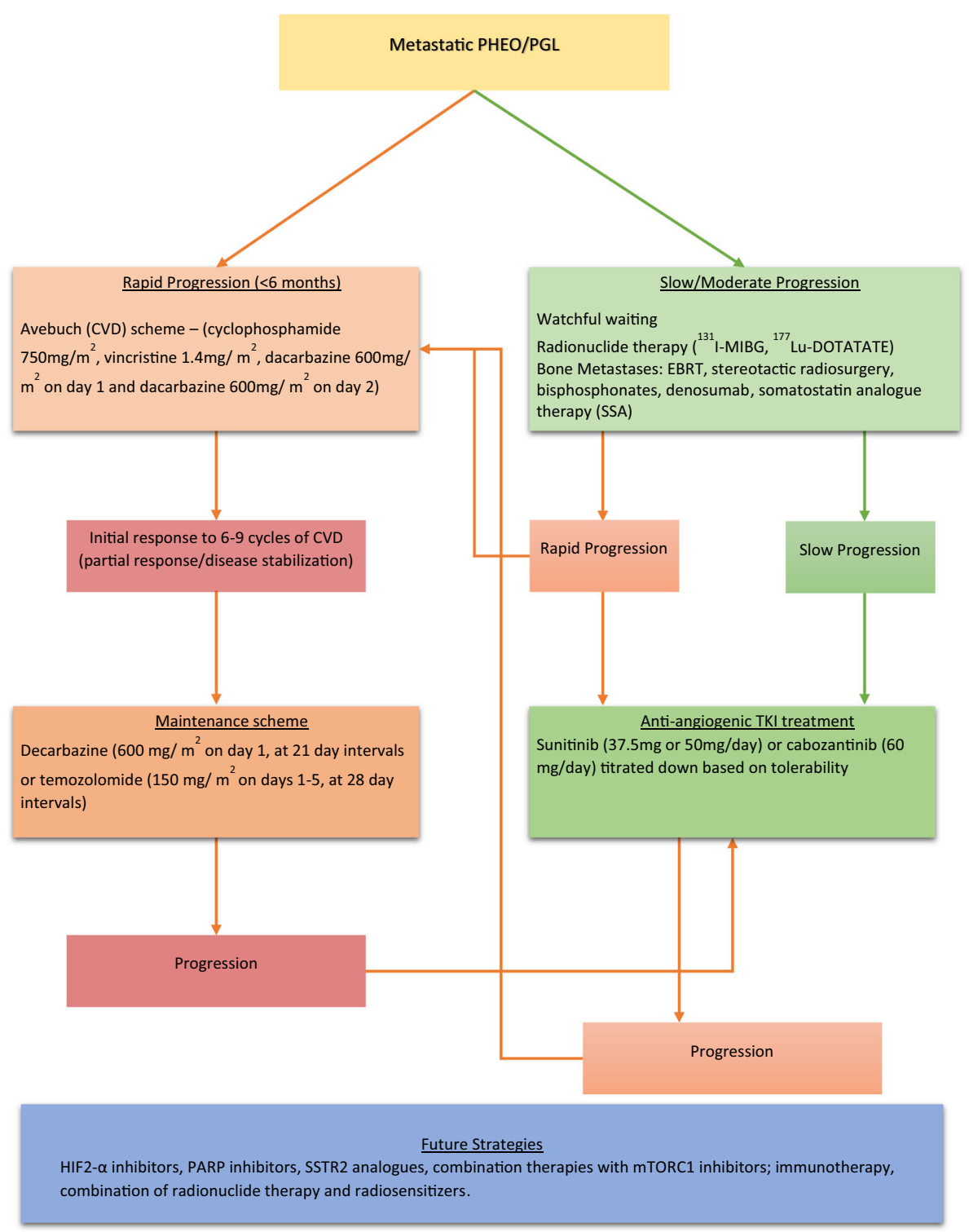

Fig. 3. Treatment algorithm for metastatic PHEO/PGL. PHE0, pheochromocytoma; PGL, paraganglioma; CVD, cyclophosphamide, vincristine, dacarbazine; I-MIBG, iodine metaiodobenzylguanidine; Lu-DOTATATE, Lutathera-DOTATATE; cEBRT, conventional external beam radiation therapy; HIF2- $\alpha$, hypoxia-inducible factor 2-alpha; PARP, poly (ADP-ribose) polymerase; SSTR2, somatostatin receptor 2; mTORC1, mammalian target of rapamycin complex 1. Modified from Nolting et al. (Cancers 2019) [18].

PT2339 and PT2385 are two selective HIF- $2 \alpha$ antagonists, which were developed and evaluated for their anti-tumor effects. In cell lines derived from VHLmutated clear cell renal cell carcinomas (ccRCCs), PT2399 demonstrated a stronger suppression effect than sunitinib [57]. In a phase I clinical trial, PT2385 showed a complete response, partial response, and stable disease in $2 \%, 12 \%$, and $52 \%$ of ccRCC patients, respectively [58]. A phase II clinical trial is currently ongoing to evaluate PT2385 in patients with VHL-mutated ccRCCs. While neither of these compounds has been used in patients with PHEO/PGL, the tumor-suppressing effects of HIF- $2 \alpha$ inhibitors in HIF-driven tumors such as 
Table 1. Ongoing clinical trials for pheochromocytoma/paraganglioma patients

\begin{tabular}{|c|c|c|c|}
\hline Therapy & Classification & Study design & Clinical trial number \\
\hline \multicolumn{4}{|l|}{ Cluster I therapies } \\
\hline Axitinib & TKI & Phase 2 & NCT03839498 \\
\hline Axitinib & TKI & Phase 2 & NCT01967576 \\
\hline Sunitinib & TKI & Phase 2 & NCT01371201 \\
\hline Sunitinib & TKI & Phase 2 & NCT00843037 \\
\hline Cabozantinib S-malate & TKI & Phase 2 & NCT02302833 \\
\hline Lenvatinib & TKI & Phase 2 & NCT03008369 \\
\hline Dovitinib & TKI & Phase 2 & NCT01635907 \\
\hline Pembrolizumab & Immunotherapy & Phase 2 & NCT02721732 \\
\hline Nivolumab, ipilimumab & Immunotherapy & Phase 2 & NCT02834013 \\
\hline \multicolumn{4}{|l|}{ Other therapies } \\
\hline 131-I MIBG & Radioiodine & $\mathrm{N} / \mathrm{A}$ & NCT01850888 \\
\hline 131-I MIBG & Radioiodine & Phase 1 & NCT03649438 \\
\hline Iobenguane I-131 & Radioiodine & Phase 2 & NCT00874614 \\
\hline Iobenguane I-131 & Radioiodine & Phase 2 & NCT00107289 \\
\hline Lanreotide & Somatostatin analogue & Phase 2 & NCT03946527 \\
\hline Lu-177-D0TATATE & PRRT & Phase 2 & NCT03206060 \\
\hline Lu-177 DOTATOC & PRRT & Phase 2 & NCT04276597 \\
\hline LU-177-DOTA-OCTREOTATE & PRRT & Phase $1 / 2$ & NCT03923257 \\
\hline E02401 Vaccine & Microbial-derived peptide vaccine & Phase $1 / 2$ & NCT04187404 \\
\hline ONC201 & DRD2 antagonist & Phase 2 & NCT03034200 \\
\hline Tipifarnib & RAS inhibitor & Phase 2 & NCT04284774 \\
\hline
\end{tabular}

ccRCCs are promising and indicate that they could have potential therapeutic options for patients with cluster I PHEO/PGL. Furthermore, cluster I mutations including $S D H B, S D H D, V H L$, and $F H$ have been associated with renal cell carcinomas, so agents that have shown efficacy with ccRCCs may warrant further study in PHEO/PGL patients [59]. Preclinically, anthracycleines (daunorubicin, doxorubicin, epirubicin, and idarubicin) have shown suppression of cell growth in metastatic PHEOs/PGLs through the inhibition of HIF-1 and HIF$2 \alpha$ and as such could be a new therapeutic option for patients with metastatic PHEO/PGL [60] (Fig. 1).

Psuedohypoxia may prevent immune recognition of cluster I PHEOs/PGLs through the inactivation of cytotoxic T cell lymphocytes, activation of immune-suppressive monocytes (M2 macrophages), and increased expression of the immune checkpoint protein programmed death-ligand 1 (PD-L1) resulting in exhaustion of tumor-infiltrating lymphocytes [61-63]. For these reasons, specific immune system modulating approaches are being introduced 
to boost the immune microenvironment in these tumors followed by the use of current immunotherapies. Two phase II clinical trials of checkpoint inhibitors (nivolumab + ipilimumab, and pembrolizumab) are currently active that include PHEOs/PGLs (Table 1) and several new approaches are being studied experimentally [64] (Fig. 1).

\section{Poly (ADP-ribose) polymerase (PARP) inhibition}

Germline loss-of-function mutations in succinate dehydrogenase, a key Krebs cycle enzyme, are linked to elevated levels of succinate [65, 66]. High levels of succinate and $\mathrm{NAD}^{+}$inhibit homologous recombination (HR)-based DNA repair [67]. Poly (ADP-ribose) polymerase (PARP) is activated after DNA damage and regulates base excision repair, homologous recombination, and nonhomologous end joining [68]. Therefore, SDH-mutated cluster I PHEOs/PGLs may be sensitive to treatment with these PARP inhibitors. Olaparib, an FDAapproved PARP inhibitor, was able to amplify the therapeutic effect of temozolomide in SDHB-mutant preclinical models [69] (Fig. 1).

\section{Kinase signaling group (cluster II) targeted therapies}

Cluster II PHEOs/PGLs, also known as the kinase signaling group, are characterized by mutations in RET, NF1, TMEM127, MAX, and HRAS [16•].

\section{Mammalian target of rapamycin (mTOR) inhibition}

Hyperactivation of kinase activity is commonly detected in the Ras/Raf/Erk or PI3K/Akt/mTOR pathways of patients with cluster II PHEO/PGL and mutations in RET, NF1, TMEM127, and MAX [70]. For this reason, kinase signaling inhibitors have been proposed for targeted therapeutics. Treatment using everolimus, an mTOR1 inhibitor, has been evaluated in patients with advanced/ metastatic PHEO/PGL [71]. In a phase II study, 5 out of 7 patients with PHEO/PGL achieved stable disease on this therapy. The median progressionfree survival was 3.8 months and the median duration of treatment was also 3.8 months for these patients [72].

\section{Wnt signaling group (cluster III) targeted therapies}

\section{Other therapies}

The Wnt signaling group (cluster III) includes mutations in the genes CSDE1 and MAM. Wnt signaling is involved not only in tumorigenesis and tumor proliferation but also in many essential physiological processes as well [73, 74]. As a result, there are no Wnt signaling-targeted therapies for PHEO/PGL patients. However, there are still many therapies that are not specific to any PHEO/PGL cluster that have shown promise for the treatment of PHEO/PGL. These therapies are described below. 
treat metastatic PHEO/PGL since 1983. In a retrospective study, a total of 116 patients were evaluated. The majority of the patients were selected for treatment based upon positive tracer uptake studies. The cumulative dose of ${ }^{131}$ I-MIBG administered ranged from 96 to $2322 \mathrm{mCi}$ (3.6 to $85.9 \mathrm{GBq}$ ), with a mean ( \pm $\mathrm{SD})$ of $490 \pm 350 \mathrm{mCi}(18.1 \pm 13.0 \mathrm{GBq})$. The subjects received a mean single therapy dose of $158 \mathrm{mCi}(5.8 \mathrm{GBq})$ and the number of doses administered ranged from 1 to 11 , with a mean of $3.3 \pm 2.2$ doses. Initial symptomatic improvement was achieved in $76 \%$ of patients, tumor responses (partial or complete response) in 30\%, and hormonal responses in $45 \%$. Five patients had complete tumor and hormonal responses, ranging from 16 to 58 months. Patients with metastases to soft tissue had more favorable responses to treatment than those with metastases to bone. No difference was noted in the ages when responders were compared with non-responders. Adverse effects, recorded in $41 \%$ of the treated patients, were generally mild except for one fatality from bone marrow aplasia. Among 89 patients with follow-up data, $45 \%$ of the responders had relapsed with recurrent or progressive disease after a mean interval of $29.3 \pm 31.1$ months (median 19 months). Of patients with an initial response to ${ }^{131}$ I-MIBG, death was reported in $33 \%$ after a mean of $23.2 \pm$ 8.1 months (median 22 months) following treatment. Of non-responders, death was reported in $45 \%$ after a mean of $14.3 \pm 8.3$ months (median 13 months) and it was concluded that ${ }^{131}$ I-MIBG therapy might be a useful palliative treatment $[39,75]$.

A meta-analysis by van Hulsteijn et al. reviewed seventeen studies encompassing a total of 243 patients with malignant PHEO/PGL who were treated with ${ }^{131}$ I-MIBG therapy. The analysis showed that stable disease could be seen in $52 \%$ of patients and a partial hormonal response in $40 \%$. The 5 -year survival rates reported were between 45 and $64 \%$. The mean progression-free survival based on two studies in the analysis was 23 months and 28 months, respectively [76].

Recently, the FDA through fast tract designation approved Azedra ${ }^{\circledR}$ (a highspecific-activity ${ }^{131}$ I-metaiodobenzylguanidine $\left({ }^{131} \mathrm{I}\right.$-MIBG) agent made of labeled ${ }^{131}$ I-MIBG molecules, allowing for lower mass doses of ${ }^{131}$ I-MIBG to be administered) for adult and pediatric patients ( $>12$ years old) with advanced, unresectable disease. The FDA approval was based on the results of a phase 2 open-label, multicenter trial that included 68 patients with pheochromocytomas or paragangliomas. The primary end point was a $>50 \%$ reduction of all antihypertensive medications lasting for at least 6 months. Twenty-five percent evaluable patients experienced a $50 \%$ or greater reduction of all antihypertensive medication for at least 6 months. Overall tumor response was achieved in $22 \%$ patients, and of those patients, 53\% experienced durable tumor responses lasting 6 months or longer. These results suggest that ${ }^{131}$ I-MIBG can have clinical benefit in patients with locally advanced or metastatic PHEO/PGL $[77,76,78]$.

Combined chemotherapy with cyclophosphamide, vincristine, and dacarbazine (CVD) has emerged as a standard option [79]. Kaiser et al. first documented that in a case series of three patients receiving CVD, a marked decrease in blood pressure and an improvement in performance status were 
achieved within the first few cycles of treatment. At a follow-up of 6 to 13 months, all three patients continued to receive chemotherapy, with further regression of tumor in two and stable disease in one. CVD was well tolerated; moderate reversible granulocytopenia, neurotoxicity, and one episode of pneumonitis were the major toxicities encountered. This report suggested that combination chemotherapy appears to be effective for symptomatic malignant pheochromocytoma [80•]. Results of a non-randomized, single-arm trial including 14 patients with confirmed metastatic PHEO/PGL and elevated urinary catecholamine secretion have been reported. After optimization of antihypertensive therapy, patients received cyclophosphamide, $750 \mathrm{mg} / \mathrm{m}^{2}$ on day 1; vincristine, $1.4 \mathrm{mg} / \mathrm{m}^{2}$ on day 1 ; and dacarbazine, $600 \mathrm{mg} / \mathrm{m}^{2}$ on days 1 and 2 , every 21 days. Combination chemotherapy with CVD produced a complete plus partial response rate of $57 \%$ (median duration, 21 months; range, 7 to more than 34). Complete and partial biochemical responses were seen in $79 \%$ of patients (median duration, more than 22 months; range, 6 to more than 35). All responding patients had objective improvement in performance status and blood pressure [81].

A long-term follow-up study was conducted in 18 patients treated with CVD at the National Institutes of Health. Combination chemotherapy with CVD produced a complete response rate of $11 \%$ and a partial response rate of $44 \%$. Median survival was 3.8 years for patients whose tumors responded to therapy and 1.8 years for patients whose tumors did not respond $(p=$ 0.65 ). All patients with tumors scored as responding reported improvement in their symptoms related to excessive catecholamine release and all had objective improvements in blood pressure. In this 22-year follow-up, there was no difference in overall survival between patients whose tumors objectively shrank and those with stable or progressive disease. However, patients reported improvement in symptoms had objective improvements in blood pressure and had tumor shrinkage that made surgical resection possible. The authors conclude that CVD therapy is not indicated in every patient with metastatic PHEOs/PGLs, but should be considered in the management of patients with symptoms and where tumor shrinkage might be beneficial [82].

A retrospective review of patients treated with CVD included 17 cases. The follow-up period after initiation of CVD ranged from 12 to 192 months (median, 60 months). Complete or partial biochemical and/or partial tumor response was achieved in $47.1 \%$ (responders). No significant biochemical or tumor response was seen in $23.5 \%$ and deterioration in biochemical and tumor outcomes was seen in $29.4 \%$ (non-responders). None of the patients showed complete biochemical and tumor responses. In responders, these effects were documented within 4 months after initiation of CVD with a progression-free survival of 31 to 60 months (median, 40 months); they also had improvements in hypertension and impaired glucose tolerance [83]. A meta-analysis consisting of four studies concerning a total of 50 patients with advanced/ metastatic PHEO/PGL showed that a partial response could be achieved in $37 \%$ of patients [84]. Anecdotal reports suggest that the efficacy of chemotherapy may be high in patients with mutations in SDHB [85]. Although the CVD regimen led to an overall response of approximately $50 \%$, it is not clear if the administration of CVD impacts overall survival, as nearly all patients develop progressive and ultimately fatal disease [82]. 
PHEO/PGL often expresses somatostatin receptor types 2 (SSTR2) and 3 (SSTR3) [86, 87]. Panntetreotide, DOTATOC, and DOTATATE are somatostatin analogs (SA) that target somatostatin receptors (SSTR). These analogs have been labeled with indium $\left({ }^{111} \mathrm{In}\right)$, gallium $\left({ }^{68} \mathrm{Ga}\right)$, yttrium $\left({ }^{90} \mathrm{Y}\right)$, and lutetium $\left({ }^{177} \mathrm{Lu}\right)$ and have been used extensively in the detection and therapy of a variety of neuroendocrine tumors [88]. A meta-analysis of studies involving advanced/ metastatic PHEO/PGL patients treated with PRRT showed that $89.8 \%$ of pooled patients had achieved disease stabilization or a partial response [31]. Menda et al. treated 17 children with neuroendocrine tumors with ${ }^{90}$ Y DOTATOC [89] including 2 patients with neuroblastoma and three with PGL. Doses ranged from 30 to $50 \mathrm{mCi} / \mathrm{m}^{2}$ per cycle with intent to deliver 3 cycles. One patient received $133 \mathrm{mCi}$ and had stable disease at the end of therapy. PGL patients received total doses ranging from 125 to $292 \mathrm{mCi}$. Two had stable disease and one had a minor response. All three PGLs had relief of bone pain and were alive at follow-up 17-84 months later.

Twelve patients with PGLs (with one PHEO) who received ${ }_{177} \mathrm{Lu}$ DOTATATE were the subject of a report by van Essen et al. [88]. These patients received single doses of $200 \mathrm{mCi}$ with intention to retreat 3 to 4 times at 610 weeks. The total doses administered ranged from 405 to $800 \mathrm{mCi}$. After treatment, 6 patients had stable disease, 1 had a partial response and 1 had minor response. The authors concluded that there was evidence of therapeutic effect, although it appeared lower than that in gastroenteropancreatic (GEP) neuroendocrine tumors (NETs). A retrospective study evaluating 28 PHEO/PGL patients treated with ${ }^{90} \mathrm{Y}$ DOTATOC [90] included 19 patients who received 2 cycles of $100 \mathrm{mCi}$ at 8 -week intervals; 6 patients received 4 cycles of $50 \mathrm{mCi} /$ $\mathrm{m}^{2}$ at 6 -week intervals, and 3 patients received 1 cycle of $100 \mathrm{mCi} / \mathrm{m}^{2}$ followed by $200 \mathrm{mCi}$ of ${ }^{177} \mathrm{Lu}$ at 8 -week intervals. There were 2 partial remissions, 5 minor responses, 2 mixed responses, and 13 patients with stable disease at restaging.

Moreover, Kong et al. reported on 20 patients with advanced/metastatic PHEO/PGL and high SSTR expression, treated with ${ }^{177}$ Lu-DOTA-octreotate to determine the efficacy of PRRT in controlling hypertension. At 3 months after PRRT, 8 of the 14 patients treated for HTN required reduced medication doses; 5 had no change in antihypertensives, and 1 was lost to follow-up. Thirty-six percent had disease regression (29\% partial and 7\% minor response) on computed tomography, with stable findings in 50\%. Three other patients had bony disease evaluable only on SSTR imaging ( 2 partial response and 1 stable). Median progression-free survival was 39 months; median overall survival was not reached (5 deaths; median follow-up, 28 months) [91].

Furthermore, a study with 22 patients with progressive or metastatic PHEOs/PGLs were treated with PRRT, with either ${ }^{90} \mathrm{Y}$-dotatate or ${ }^{177} \mathrm{Lu}$ dotatate, or with ${ }^{131}$ I-MIBG treatment. Patients treated with PRRT had increased PFS and response to treatment compared with ${ }^{131}$ I-MIBG-treated patients ( $p$ $<0.05)$. However, there were no overall survival differences [92]. Currently, there is an ongoing trial with ${ }^{177} \mathrm{Lu}$-dotatate for inoperable PHEO/PGL (NCT03206060).

Somatostatin agonists such as lanreotide or long-acting octreotide in combination therapy and/or maintenance therapy may play a significant role in 
tumor control in patients with GEP-NET who are undergoing PRRT treatment [93, 94]; however, the clinical benefit in PHEO/PGL is unclear and further studies are warranted.

Temozolomide (TMZ) is a 3-methyl analogue of mitozolomide, which was developed as an orally administered alternative to intravenous dacarbazine [95] and has shown antitumor activity similar to dacarbazine in the treatment of melanoma [96]. The efficacy of TMZ for the treatment of glioblastoma and neuroendocrine tumors is correlated with the expression of $\mathrm{O}(6)$ methylguanine-DNA methyltransferase (MGMT) and/or MGMT promoter methylation $[75,97]$.

More recently, a retrospective study showed therapeutic benefit of TMZ in patients with metastatic PGL. There was a correlation between SDHB mutation and $\mathrm{O}(6)$-methylguanine-DNA methyltransferase (MGMT) promoter methylation and MGMT expression and response to temozolomide in the French nationwide independent cohort of 190 PHEOs or PGLs. PFS according to RECIST 1.1 and PERCIST 1.0 criteria was the primary end point. Fifteen consecutive patients with metastatic PGL were enrolled; ten (67\%) carried a mutation in $S D H B$. The mean dose intensity of TMZ was $172 \mathrm{mg} / \mathrm{m}^{2}$ daily for 5 days every 28 days. Median PFS was 13.3 months after a median follow-up of 35 months. There were five partial responses (33\%), seven stable (47\%), and three progressive diseases (20\%). The grade 3 toxicities observed were lymphopenia in two patients and hypertension in one. Partial responses were observed only in patients with a mutation in SDHB. MGMT immunohistochemistry was negative in tumor samples from four patients who responded to treatment. SDHB germline mutation was associated with hypermethylation of the MGMT promoter and low expression of MGMT in 190 samples of the French nationwide independent cohort [98]. This study demonstrates that TMZ is an effective antitumor agent in patients with SDHB-related metastatic PGL. The silencing of MGMT expression as a consequence of MGMT promoter hypermethylation in $S D H B$-mutated tumors may explain this finding.

Furthermore, an anecdotal report of a case with metastatic PGL to the liver suggested that an oral regimen of temozolomide is associated with antitumor activity. In this report, short-term treatment resulted in significant clinical improvement, a catecholamine secretory reduction rate of $75 \%$, and normalization of abnormal hepatic function. In addition, there were minimal, but measurable, reductions in the sizes of the primary tumor and hepatic metastases. The clinical improvement and biochemical responses allowed for a surgical debulking procedure to proceed successfully without any complications [99].

Two anecdotal reports describe cases of SDHB PGL who responded to regimens of metronomic TMZ and high-dose lanreotide. One patient achieved progression-free survival for 13 months, and the second patient remained under treatment after 27 months of stable disease. Treatment was well tolerated in both cases [100]. As previously discussed, olaparib, an FDA-approved PARP inhibitor, was able to amplify the therapeutic effect of temozolomide in SDHBmutant preclinical models [69]. Furthermore, the combination of PARP inhibitors and TMZ has been evaluated in other types of solid tumors. Farago et al. recently reported a phase I/II trial of combination olaparib with TMZ in patients 
with small cell lung cancer (SCLC). They established the recommended phase II dose of olaparib $200 \mathrm{mg}$ orally twice daily in combination with temozolomide $75 \mathrm{mg} / \mathrm{m}^{2}$ daily, on days 1 to 7 of a 21-day cycle. However, further studies are warranted with this treatment modality in patients with metastatic PHEO/PGL [101].

\section{Conclusions}

New treatments are emerging for patients with advanced/metastatic PHEO/PGL. PHEO/PGL tumors that are driven by germline mutations can be grouped into three different genetic clusters. Certain therapies may be more effective based on the underlying genetic mutation of the tumor. Although retroprospective analyses demonstrate that the CVD regimen results in an overall response of approximately $40-50 \%$, there are multiple limitations in the data supporting this conclusion and the therapeutic potential of CVD. These limitations include the small size of the studies, the retrospective analyses, the absence of impact on overall survival, and the associated toxicity profile. Although the FDA approval of Azedra ${ }^{\circledR}$ provides a therapeutic alternative, the accessibility to this treatment modality remains limited. Given these limitations, new therapeutic approaches are necessary to improve overall survival and quality of life in patients with advanced/metastatic PHEO/PGL.

\section{Funding information}

The research reported in this publication was supported in part by the Center for Cancer Research, National Cancer Institute (NCI) of the National Institutes of Health (NIH) and the Cancer Moonshot Initiative ${ }^{\mathrm{SM}}$.

\section{Compliance with Ethical Standards}

\section{Conflict of Interest}

Maran Ilanchezhian declares that he has no conflict of interest. Abhishek Jha declares that he has no conflict of interest. Karel Pacak declares that he has no conflict of interest. Jaydira Del Rivero declares that she has no conflict of interest.

Human and Animal Rights and Informed Consent

This article does not contain any studies with human or animal subjects performed by any of the authors.

\section{Open Access}

This article is licensed under a Creative Commons Attribution 4.0 International License, which permits use, sharing, adaptation, distribution and reproduction in any medium or format, as long as you give appropriate credit to the original author(s) and the source, provide a link to the Creative Commons licence, and indicate if changes were made. The images or other third party material in this article are included in the article's Creative Commons licence, unless indicated otherwise in a credit line to the material. If material is not included in the article's Creative Commons licence and your intended use is not permitted by statutory regulation or exceeds 
the permitted use, you will need to obtain permission directly from the copyright holder. To view a copy of this licence, visit http://creativecommons.org/licenses/by/4.0/.

\section{References and Recommended Reading}

Papers of particular interest, published recently, have been highlighted as:

- Of importance

$\bullet \quad$ Of major importance

1. Lenders JW, Eisenhofer G, Mannelli M, Pacak K. Phaeochromocytoma. Lancet (London, England). 2005;366(9486):665-75. https://doi.org/10.1016/ s0140-6736(05)67139-5.

2. DeLellis RA. Pathology and genetics of tumours of endocrine organs. IARC; 2004.

3. Erickson D, Kudva YC, Ebersold MJ, Thompson GB, Grant CS, van Heerden JA, et al. Benign paragangliomas: clinical presentation and treatment outcomes in $236 \mathrm{pa}-$ tients. J Clin Endocrinol Metab. 2001;86(11):5210-6. https://doi.org/10.1210/jcem.86.11.8034.

4. Guerrero MA, Schreinemakers JM, Vriens MR, Suh I, Hwang J, Shen WT, et al. Clinical spectrum of pheochromocytoma. J Am Coll Surg. 2009;209(6):727-32. https://doi.org/10.1016/j.jamcollsurg.2009.09.022.

5. Bravo EL. Pheochromocytoma: new concepts and future trends. Kidney Int. 1991;40(3):544-56. https:// doi.org/10.1038/ki.1991.244.

6. Lenders JW, Pacak K, Walther MM, Linehan WM, Mannelli M, Friberg P, et al. Biochemical diagnosis of pheochromocytoma: which test is best. Jama. 2002;287(11):1427-34. https://doi.org/10.1001/ jama.287.11.1427.

7. Baudin E, Habra MA, Deschamps F, Cote G, Dumont F, Cabanillas $\mathrm{M}$, et al. Therapy of endocrine disease: treatment of malignant pheochromocytoma and paraganglioma. Eur J Endocrinol. 2014;171(3):R11122. https://doi.org/10.1530/eje-14-0113.

8. Hescot S, Leboulleux S, Amar L, Vezzosi D, Borget I, Bournaud-Salinas $\mathrm{C}$, et al. One-year progression-free survival of therapy-naive patients with malignant pheochromocytoma and paraganglioma. J Clin Endocrinol Metab. 2013;98(10):4006-12. https://doi. org/10.1210/jc.2013-1907.

9. Jimenez C, Rohren E, Habra MA, Rich T, Jimenez P, Ayala-Ramirez $\mathrm{M}$, et al. Current and future treatments for malignant pheochromocytoma and sympathetic paraganglioma. Curr Oncol Rep. 2013;15(4):356-71. https://doi.org/10.1007/s11912-013-0320-x.

10. Jimenez P, Tatsui C, Jessop A, Thosani S, Jimenez C. Treatment for malignant pheochromocytomas and paragangliomas: 5 years of progress. Curr Oncol Rep. 2017;19(12):83. https://doi.org/10.1007/s11912-0170643-0.

11. Plouin PF, Fitzgerald P, Rich T, Ayala-Ramirez M, Perrier ND, Baudin E, et al. Metastatic pheochromocytoma and paraganglioma: focus on therapeutics. Hormone Metab Res $=$ Hormon- und Stoffwechselforschung $=$ Hormones et metabolisme. 2012;44(5):390-9. https://doi.org/10. 1055/s-0031-1,299,707.

12. Adjallé R, Plouin PF, Pacak K, Lehnert H. Treatment of malignant pheochromocytoma. Hormone and metabolic research $=$ Hormon- und Stoffwechselforschung = Hormones et metabolisme. 2009;41(9):687-96. https://doi.org/10.1055/s-0029-1,231,025.

13. Luchetti A, Walsh D, Rodger F, Clark G, Martin T, Irving R, et al. Profiling of somatic mutations in phaeochromo cytoma and paraganglioma by targeted next generation sequencing analysis. Int J Endocrinol. 2015;2015:138573. https://doi.org/10.1155/2015/138573.

14. Gupta G, Pacak K. Precision medicine: an update on genotype/biochemical phenotype relationships in pheochromocytoma/paraganglioma patients. Endocr Pract: official journal of the American College of Endocrinology and the American Association of Clinical Endocrinologists. 2017;23(6):690-704. https://doi. org/10.4158/ep161718.Ra.

15. Pillai S, Gopalan V, Smith RA, Lam AK. Updates on the genetics and the clinical impacts on phaeochromocytoma and paraganglioma in the new era. Crit Rev Oncol Hematol. 2016;100:190-208. https://doi.org/10.1016/j.critrevonc.2016.01.022.

16. Crona J, Taïeb D, Pacak K. New Perspectives on pheochromocytoma and paraganglioma: toward a molecular classification. Endocr Rev. 2017;38(6):489-515.

https://doi.org/10.1210/er.2017-00062 Retrospective study detailing the differences between sporadic and SDHB germline PHEOs/PGLs.

17.• Nölting S, Ullrich M, Pietzsch J, Ziegler CG, Eisenhofer G, Grossman A, et al. Current management of pheochromocytoma/paraganglioma: a guide for the practicing clinician in the era of precision medicine. Cancers. 2019;11(10):1505.

https://doi.org/10.3390/cancers11101505 Retrospective study detailing the differences between sporadic and SDHB germline PHEOs/PGLs.

18. Alrezk R, Suarez A, Tena I, Pacak K. Update of pheochromocytoma syndromes: genetics, biochemical evaluation, and imaging. Front Endocrinol. 2018;9:515. https://doi. org/10.3389/fendo.2018.00515.

19.• Jochmanova I, Pacak K. Genomic landscape of pheochromocytoma and paraganglioma. Trends in cancer. 2018;4(1):6-9.

https://doi.org/10.1016/j.trecan.2017.11.001 Retrospective study detailing the differences between sporadic and SDHB germline PHEOs/PGLs. 
20. Burnichon N, Vescovo L, Amar L, Libé R, de Reynies A, Venisse A, et al. Integrative genomic analysis reveals somatic mutations in pheochromocytoma and paraganglioma. Hum Mol Genet. 2011;20(20):397485. https://doi.org/10.1093/hmg/ddr324.

21. Fishbein L, Leshchiner I, Walter V, Danilova L, Robertson AG, Johnson AR, et al. Comprehensive molecular characterization of pheochromocytoma and paraganglioma. Cancer Cell. 2017;31(2):181-93. https://doi.org/10.1016/j.ccell.2017.01.001.

22. Astuti D, Latif F, Dallol A, Dahia PL, Douglas F, George $\mathrm{E}$, et al. Gene mutations in the succinate dehydrogenase subunit SDHB cause susceptibility to familial pheochromocytoma and to familial paraganglioma. Am J Hum Genet. 2001;69(1):49-54. https://doi.org/ 10.1086/321282.

23. Amar L, Baudin E, Burnichon N, Peyrard S, Silvera S, Bertherat J, et al. Succinate dehydrogenase B gene mutations predict survival in patients with malignant pheochromocytomas or paragangliomas. J Clin Endocrinol Metab. 2007;92(10):3822-8. https://doi. org/10.1210/jc.2007-0709.

24. Benn DE, Gimenez-Roqueplo AP, Reilly JR, Bertherat J, Burgess J, Byth $\mathrm{K}$, et al. Clinical presentation and penetrance of pheochromocytoma/paraganglioma syndromes. J Clin Endocrinol Metab. 2006;91(3):827-36. https://doi.org/10.1210/jc.2005-1862.

25. Brouwers FM, Eisenhofer G, Tao JJ, Kant JA, Adams KT, Linehan WM, et al. High frequency of SDHB germline mutations in patients with malignant catecholamineproducing paragangliomas: implications for genetic testing. J Clin Endocrinol Metab. 2006;91(11):4505-9. https://doi.org/10.1210/jc.2006-0423.

26.• Turkova H, Prodanov T, Maly M, Martucci V, Adams K, Widimsky J Jr, et al. Characteristics and outcomes of metastatic SDHB and sporadic pheochromocytoma/ paraganglioma: an national institutes of health study. Endocr Pract: official journal of the American College of Endocrinology and the American Association of Clinical Endocrinologists. 2016;22(3):302-14.

https://doi.org/10.4158/ep15725.Or Retrospective study detailing the differences between sporadic and SDHB germline PHEOs/PGLs.

27. Amar L, Bertherat J, Baudin E, Ajzenberg C, Bressac-de Paillerets B, Chabre O, et al. Genetic testing in pheochromocytoma or functional paraganglioma. J Clin Oncol Off J Am Soc Clin Oncol. 2005;23(34):8812-8. https://doi.org/10.1200/JCO.2005.03.1484.

28. Timmers HJ, Chen CC, Carrasquillo JA, Whatley M, Ling A, Eisenhofer G, et al. Staging and functional characterization of pheochromocytoma and paraganglioma by $18 \mathrm{~F}-$ fluorodeoxyglucose (18F-FDG) positron emission tomography. J Natl Cancer Inst. 2012;104(9):700-8. https://doi. org/10.1093/jnci/djs188.

29. Jha A, de Luna K, Balili CA, Millo C, Paraiso CA, Ling A, et al. Clinical, diagnostic, and treatment characteristics of SDHA-related metastatic pheochromocytoma and paraganglioma. Front Oncol. 2019;9:53. https://doi. org/10.3389/fonc.2019.00053.
30. Sawka AM, Jaeschke R, Singh RJ, Young WF Jr. A comparison of biochemical tests for pheochromocytoma: measurement of fractionated plasma metanephrines compared with the combination of 24-h urinary metanephrines and catecholamines. J Clin Endocrinol Metab. 2003;88(2):553-8. https://doi.org/10.1210/jc. 2002-021251.

31. Taïeb D, Jha A, Treglia G, Pacak K. Molecular imaging and radionuclide therapy of pheochromocytoma and paraganglioma in the era of genomic characterization of disease subgroups. Endocr Relat Cancer. 2019;26(11):R627-r52. https://doi.org/10.1530/erc19-0165.

32. Taïeb D, Hicks RJ, Hindié E, Guillet BA, Avram A, Ghedini P, et al. European Association of Nuclear Medicine Practice Guideline/Society of Nuclear Medicine and Molecular Imaging Procedure Standard 2019 for radionuclide imaging of phaeochromocytoma and paraganglioma. Eur J Nucl Med Mol Imaging. 2019;46(10):2112-37. https://doi.org/10.1007/ s00259-019-04398-1.

33. Young AL, Baysal BE, Deb A, Young WF Jr. Familial malignant catecholamine-secreting paraganglioma with prolonged survival associated with mutation in the succinate dehydrogenase B gene. J Clin Endocrinol Metab. 2002;87(9):4101-5. https://doi.org/10.1210/ jc. 2002-020312.

34. Eisenhofer G, Lenders JW, Siegert G, Bornstein SR, Friberg P, Milosevic D, et al. Plasma methoxytyramine: a novel biomarker of metastatic pheochromocytoma and paraganglioma in relation to established risk factors of tumour size, location and SDHB mutation status. Eur J Cancer. 2012;48(11):1739-49. https://doi. org/10.1016/j.ejca.2011.07.016.

35. O'Riordain DS, Young WF Jr, Grant CS, Carney JA, van Heerden JA. Clinical spectrum and outcome of functional extraadrenal paraganglioma. World J Surg. 1996;20(7):916-21 discussion 22.

36. Zelinka T, Musil Z, Duskova J, Burton D, Merino MJ, Milosevic D, et al. Metastatic pheochromocytoma: does the size and age matter. Eur J Clin Investig. 2011;41(10):1121-8. https://doi.org/10.1111/j.13652362.2011.02518.x.

37. Eisenhofer G, Lenders JW, Timmers H, Mannelli M, Grebe SK, Hofbauer LC, et al. Measurements of plasma methoxytyramine, normetanephrine, and metanephrine as discriminators of different hereditary forms of pheochromocytoma. Clin Chem. 2011;57(3):411-20. https://doi.org/10.1373/ clinchem.2010.153320.

38. Ayala-Ramirez M, Feng L, Johnson MM, Ejaz S, Habra MA, Rich T, et al. Clinical risk factors for malignancy and overall survival in patients with pheochromocytomas and sympathetic paragangliomas: primary tumor size and primary tumor location as prognostic indicators. J Clin Endocrinol Metab. 2011;96(3):71725. https://doi.org/10.1210/jc.2010-1946.

39. Loh KC, Fitzgerald PA, Matthay KK, Yeo PP, Price DC. The treatment of malignant pheochromocytoma with 
iodine-131 metaiodobenzylguanidine (131I-MIBG): a comprehensive review of 116 reported patients. J Endocrinol Investig. 1997;20(11):648-58.

40. Makeieff M, Raingeard I, Alric P, Bonafe A, Guerrier B, Marty-Ane C. Surgical management of carotid body tumors. Ann Surg Oncol. 2008;15(8):2180-6. https:// doi.org/10.1245/s10434-008-9977-z.

41. Lin F, Rivero JD, Carrasquillo JA, Jha A, Gonzales MK, Lindenberg L, et al. Phase 2 trial of Lu-177-DOTATATE in inoperable pheochromocytoma/paraganglioma. J Clin Oncol. 2019;37(15_suppl):TPS4159-TPS. https:// doi.org/10.1200/JCO.2019.37.15_suppl.TPS4159.

42. Satapathy S, Mittal BR, Bhansali A. Peptide receptor radionuclide therapy in the management of advanced pheochromocytoma and paraganglioma: a systematic review and meta-analysis. Clin Endocrinol. 2019;91(6):718-27. https://doi.org/10.1111/cen.14106.

43. Pacak K, Del Rivero J. Pheochromocytoma. In: Feingold KR, Anawalt B, Boyce A, Chrousos G, Dungan K, Grossman A et al., editors. Endotext. South Dartmouth (MA): MDText.com, Inc. Copyright ${ }^{\odot}$ 20002020, MDText.com, Inc.; 2000. Accessed 23 March 2020.

44. Favier J, Igaz P, Burnichon N, Amar L, Libé R, Badoual $\mathrm{C}$, et al. Rationale for anti-angiogenic therapy in pheochromocytoma and paraganglioma. Endocr Pathol. 2012;23(1):34-42. https://doi.org/10.1007/ s12022-011-9189-0.

45. Pang Y, Liu Y, Pacak K, Yang C. Pheochromocytomas and paragangliomas: from genetic diversity to targeted therapies. Cancers. 2019;11(4):436. https://doi.org/ $10.3390 /$ cancers 11040436 .

46. Ferreira CV, Siqueira DR, Romitti M, Ceolin L, Brasil BA, Meurer L, et al. Role of VEGF-A and its receptors in sporadic and MEN2-associated pheochromocytoma. Int J Mol Sci. 2014;15(4):5323-36. https://doi.org/10. 3390/ijms15045323.

47. Ayala-Ramirez M, Chougnet CN, Habra MA, Palmer JL, Leboulleux S, Cabanillas ME, et al. Treatment with sunitinib for patients with progressive metastatic pheochromocytomas and sympathetic paragangliomas. J Clin Endocrinol Metab. 2012;97(11):4040-50. https://doi. org/10.1210/jc.2012-2356.

48. Hahn NM, Reckova M, Cheng L, Baldridge LA, Cummings OW, Sweeney CJ. Patient with malignant paraganglioma responding to the multikinase inhibitor sunitinib malate. J Clin Oncol Off J Am Soc Clin Oncol. 2009;27(3):460-3. https://doi.org/10.1200/jco.2008.19.9380.

49. Jimenez C, Cabanillas ME, Santarpia L, Jonasch E, Kyle $\mathrm{KL}$, Lano EA, et al. Use of the tyrosine kinase inhibitor sunitinib in a patient with von Hippel-Lindau disease: targeting angiogenic factors in pheochromocytoma and other von Hippel-Lindau disease-related tumors. J Clin Endocrinol Metab. 2009;94(2):386-91. https:// doi.org/10.1210/jc.2008-1972.

50. Nemoto K, Miura T, Shioji G, Tsuboi N. Sunitinib treatment for refractory malignant pheochromocytoma. Neuro Endocrinol Lett. 2012;33(3):260-4.
51. O'Kane GM, Ezzat S, Joshua AM, Bourdeau I, Leibowitz-Amit R, Olney HJ, et al. A phase 2 trial of sunitinib in patients with progressive paraganglioma or pheochromocytoma: the SNIPP trial. Br J Cancer. 2019;120(12):1113-9.

52. Pichun MEB, Edgerly M, Velarde M, Bates SE, Daerr R, Adams K, et al. Phase II clinical trial of axitinib in metastatic pheochromocytomas and paraganlgiomas $(\mathrm{P} / \mathrm{PG})$ : preliminary results. J Clin Oncol. 2015;33(7_suppl):457. https://doi.org/10.1200/jco. 2015.33.7_suppl.457.

53. Zhuang Z, Yang C, Lorenzo F, Merino M, Fojo T, Kebebew E, et al. Somatic HIF2A gain-of-function mutations in paraganglioma with polycythemia. $\mathrm{N}$ Engl J Med. 2012;367(10):922-30. https://doi.org/10. 1056/NEJMoa1205119.

54. Jochmanova I, Lazurova I. A new twist in neuroendocrine tumor research: Pacak-Zhuang syndrome, HIF2alpha as the major player in its pathogenesis and future therapeutic options. Biomed Papers Med Fac Univ Palacky Olomouc Czech Repub. 2014;158(2):175-80. https://doi.org/10.5507/bp. 2014.021 .

55. Jochmanova I, Zelinka T, Widimsky J Jr, Pacak K. HIF signaling pathway in pheochromocytoma and other neuroendocrine tumors. Physiol Res. 2014;63(Suppl 2):S251-62.

56. Toledo R, Jimenez C. Recent advances in the management of malignant pheochromocytoma and paraganglioma: focus on tyrosine kinase and hypoxiainducible factor inhibitors. F1000Res. 2018;7:F1000 Faculty Rev-148. https://doi.org/10.12688/ f1000research.13995.1.

57. Chen W, Hill H, Christie A, Kim MS, Holloman E, Pavia-Jimenez A, et al. Targeting renal cell carcinoma with a HIF-2 antagonist. Nature. 2016;539(7627):112-7. https://doi.org/10.1038/ nature 19796.

58. Courtney KD, Infante JR, Lam ET, Figlin RA, Rini BI, Brugarolas J, et al. Phase I dose-escalation trial of PT2385, a first-in-class hypoxia-inducible factor-2alpha antagonist in patients with previously treated advanced clear cell renal cell carcinoma. J Clin Oncol Off J Am Soc Clin Oncol. 2018;36(9):867-74. https://doi. org/10.1200/jco.2017.74.2627.

59. Haas NB, Nathanson KL. Hereditary kidney cancer syndromes. Adv Chronic Kidney Dis. 2014;21(1):8190. https://doi.org/10.1053/j.ackd.2013.10.001.

60. Pang Y, Yang C, Schovanek J, Wang H, Bullova P, Caisova V, et al. Anthracyclines suppress pheochromocytoma cell characteristics, including metastasis, through inhibition of the hypoxia signaling pathway. Oncotarget. 2017;8(14):22313-24. https://doi.org/10. 18632/oncotarget.16224.

61. Chouaib S, Noman MZ, Kosmatopoulos K, Curran MA. Hypoxic stress: obstacles and opportunities for innovative immunotherapy of cancer. Oncogene. 2017;36(4):439-45. https://doi.org/10.1038/onc. 2016.225 . 
62. Hatfield SM, Sitkovsky M. A2A adenosine receptor antagonists to weaken the hypoxia-HIF- $1 \alpha$ driven immunosuppression and improve immunotherapies of cancer. Current opinion in pharmacology. Curr Opin Pharmacol. 2016;29:90-6. https://doi.org/10.1016/j. coph.2016.06.009.

63. Labiano S, Palazón A, Bolaños E, Azpilikueta A, Sánchez-Paulete AR, Morales-Kastresana A, et al. Hypoxia-induced soluble CD137 in malignant cells blocks CD137L-costimulation as an immune escape mechanism. Oncoimmunology. 2016;5(1):e1062967. https://doi.org/10.1080/2162402x.2015.1062967.

64. Caisova V, Li L, Gupta G, Jochmanova I, Jha A, Uher O, et al. The significant reduction or complete eradication of subcutaneous and metastatic lesions in a pheochromocytoma mouse model after immunotherapy using mannan-BAM, TLR ligands, and anti-CD40. Cancers. 2019;11(5):654. https://doi.org/10.3390/ cancers 11050654 .

65. Buffet A, Venisse A, Nau V, Roncellin I, Boccio V, Le Pottier N, et al. A decade (2001-2010) of genetic testing for pheochromocytoma and paraganglioma. Hormone Metab Res = Hormon- und Stoffwechselforschung = Hormones et metabolisme. 2012;44(5):359-66. https://doi.org/10.1055/s-0032-1,304,594.

66. Schimke RN, Collins DL, Stolle CA. Paraganglioma, neuroblastoma, and a SDHB mutation: resolution of a 30-year-old mystery. Am J Med Genet A.

2010;152a(6):1531-5. https://doi.org/10.1002/ajmg. a.33384.

67. Sulkowski PL, Sundaram RK, Oeck S, Corso CD, Liu Y, Noorbakhsh S, et al. Krebs-cycle-deficient hereditary cancer syndromes are defined by defects in homologous-recombination DNA repair. Nat Genet. 2018;50(8):1086-92. https://doi.org/10.1038/ s41588-018-0170-4.

68. Pascal JM. The comings and goings of PARP-1 in response to DNA damage. DNA Repair (Amst). 2018;71:177-82. https://doi.org/10.1016/j.dnarep. 2018.08.022.

69. Pang Y, Lu Y, Caisova V, Liu Y, Bullova P, Huynh TT, et al. Targeting $\mathrm{NAD}(+) / \mathrm{PARP}$ DNA repair pathway as a novel therapeutic approach to SDHB-mutated cluster I pheochromocytoma and paraganglioma. Clin Cancer Res: an official journal of the American Association for Cancer Research. 2018;24(14):3423-32. https://doi. org/10.1158/1078-0432.Ccr-17-3406.

70. Ma XM, Blenis J. Molecular mechanisms of mTORmediated translational control. Nature reviews. Mol Cell Biol. 2009;10(5):307-18. https://doi.org/10. 1038/nrm 2672 .

71. Druce MR, Kaltsas GA, Fraenkel M, Gross DJ, Grossman AB. Novel and evolving therapies in the treatment of malignant phaeochromocytoma: experience with the mTOR inhibitor everolimus (RAD001). Hormone Metab Res = Hormon- und Stoffwechselforschung $=$ Hormones et metabolisme. 2009;41(9):697-702. https://doi.org/10.1055/s-0029$1,220,687$.
72. Oh DY, Kim TW, Park YS, Shin SJ, Shin SH, Song EK, et al. Phase 2 study of everolimus monotherapy in patients with nonfunctioning neuroendocrine tumors or pheochromocytomas/paragangliomas. Cancer. 2012;118(24):6162-70. https://doi.org/10.1002/cncr. 27675.

73. Kahn M. Can we safely target the WNT pathway. Nat Rev Drug Discov. 2014;13(7):513-32. https://doi.org/ $10.1038 / \operatorname{nrd} 4233$.

74. Martin-Orozco E, Sanchez-Fernandez A, Ortiz-Parra I, Ayala-San Nicolas M. WNT signaling in tumors: the way to evade drugs and immunity. Front Immunol. 2019;10(2854):2854. https://doi.org/10.3389/fimmu. 2019.02854 .

75. Hegi ME, Diserens AC, Gorlia T, Hamou MF, de Tribolet N, Weller M, et al. MGMT gene silencing and benefit from temozolomide in glioblastoma. $\mathrm{N}$ Engl J Med. 2005;352(10):997-1003. https://doi.org/10. 1056/NEJMoa043331.

76. van Hulsteijn LT, Niemeijer ND, Dekkers OM, Corssmit EP. (131)I-MIBG therapy for malignant paraganglioma and phaeochromocytoma: systematic review and meta-analysis. Clin Endocrinol. 2014;80(4):487-501. https://doi.org/10.1111/cen. 12341.

77. FDA approves AZEDRA specified use in pheochromocytomas/paragangliomas. J Nucl Med. 2018;59(10):17. https://pubmed.ncbi.nlm.nih.gov/ $30275289 /$.

78. Pryma D, Chin B, Noto R, Dillon J, Solnes L, Jensen J, et al. An update on overall survival from a multi-center, open-label, pivotal phase $2 \mathrm{~b}$ study of AZEDRA ${ }^{\circledR}$ (iobenguane I 131) in patients with iobenguane scan positive locally advanced or metastatic pheochromocytoma/paraganglioma (PPGL). J Nucl Med. 2019;60(supplement 1):564.

79. Grogan RH, Mitmaker EJ, Duh QY. Changing paradigms in the treatment of malignant pheochromocytoma. Cancer Control: journal of the Moffitt Cancer Center. 2011;18(2):104-12.

80. Keiser HR, Goldstein DS, Wade JL, Douglas FL, Averbuch SD. Treatment of malignant pheochromocytoma with combination chemotherapy. Hypertension. 1985;7(3 Pt 2):I18-24.

Nonrandomized, single-arm trial determining the efficacy of CVD combination chemotherapy in advanced PHEO.

81. Averbuch SD, Steakley CS, Young RC, Gelmann EP, Goldstein DS, Stull R, et al. Malignant pheochromocytoma: effective treatment with a combination of cyclophosphamide, vincristine, and dacarbazine. Ann Intern Med. 1988;109(4):267-73.

82. Huang H, Abraham J, Hung E, Averbuch S, Merino M, Steinberg SM, et al. Treatment of malignant pheochromocytoma/paraganglioma with cyclophosphamide, vincristine, and dacarbazine: recommendation from a 22-year follow-up of 18 patients. Cancer. 2008;113(8):2020-8. https://doi.org/10.1002/cncr. 23812. 
83. Tanabe A, Naruse $M$, Nomura K, Tsuiki $M$, Tsumagari A, Ichihara A. Combination chemotherapy with cyclophosphamide, vincristine, and dacarbazine in patients with malignant pheochromocytoma and paraganglioma. Hormones \& cancer. 2013;4(2):10310. https://doi.org/10.1007/s12672-013-0133-2.

84. Niemeijer ND, Alblas G, van Hulsteijn LT, Dekkers OM, Corssmit EP. Chemotherapy with cyclophosphamide, vincristine and dacarbazine for malignant paraganglioma and pheochromocytoma: systematic review and metaanalysis. Clin Endocrinol. 2014;81(5):642-51. https:// doi.org/10.1111/cen.12542.

85. He J, Makey D, Fojo T, Adams KT, Havekes B, Eisenhofer G, et al. Successful chemotherapy of hepatic metastases in a case of succinate dehydrogenase subunit B-related paraganglioma. Endocrine. 2009;36(2):189-93. https://doi.org/10.1007/s12020009-9219-6.

86. Reubi JC, Waser B, Schaer JC, Laissue JA. Somatostatin receptor sst1-sst5 expression in normal and neoplastic human tissues using receptor autoradiography with subtype-selective ligands. Eur J Nucl Med. 2001;28(7):836-46.

87. Mundschenk J, Unger N, Schulz S, Hollt V, Schulz S, Steinke R, et al. Somatostatin receptor subtypes in human pheochromocytoma: subcellular expression pattern and functional relevance for octreotide scintigraphy. J Clin Endocrinol Metab. 2003;88(11):5150-7. https://doi.org/10.1210/jc.2003-030262.

88. van Essen M, Krenning EP, Kooij PP, Bakker WH, Feelders RA, de Herder WW, et al. Effects of therapy with [177LuDOTA0, Tyr3]octreotate in patients with paraganglioma, meningioma, small cell lung carcinoma, and melanoma. J Nud Med. 2006;47(10):1599-606.

89. Menda Y, O'Dorisio MS, Kao S, Khanna G, Michael S, Connolly $\mathrm{M}$, et al. Phase I trial of 90Y-DOTATOC therapy in children and young adults with refractory solid tumors that express somatostatin receptors. J Nucl Med. 2010;51(10):1524-31. https://doi.org/10. 2967/jnumed.110.075226.

90. Forrer F, Riedweg I, Maecke HR, Mueller-Brand J. Radiolabeled DOTATOC in patients with advanced paraganglioma and pheochromocytoma. Q J Nucl Med Mol Imaging. 2008;52(4):334-40.

91. Kong G, Grozinsky-Glasberg S, Hofman MS, Callahan J, Meirovitz A, Maimon O, et al. Efficacy of peptide receptor radionuclide therapy for functional metastatic paraganglioma and pheochromocytoma. J Clin Endocrinol Metab. 2017;102(9):3278-87. https://doi. org/10.1210/jc.2017-00816.

92. Nastos K, Cheung VTF, Toumpanakis C, Navalkissoor S, Quigley AM, Caplin M, et al. Peptide receptor radionuclide treatment and (131)I-MIBG in the management of patients with metastatic/progressive phaeochromocytomas and paragangliomas. J Surg Oncol. 2017;115(4):425-34. https://doi.org/10.1002/ jso. 24553 .

93. Stueven AK, Kayser A, Wetz C, Amthauer H, Wree A, Tacke F, et al. Somatostatin analogues in the treatment of neuroendocrine tumors: past, present and future. Int J Mol Sci. 2019;20(12):3049. https://doi.org/10.3390/ ijms20123049.

94. Jha A, Patel M, Baker E, Gonzales MK, Ling A, Millo C, et al. Role of (68)Ga-DOTATATE PET/CT in a case of SDHB-related pterygopalatine fossa paraganglioma successfully controlled with octreotide. Nucl Med Mol Imaging. 2020;54(1):48-52. https://doi.org/10.1007/ s13139-019-00629-3.

95. Dhodapkar M, Rubin J, Reid JM, Burch PA, Pitot HC, Buckner JC, et al. Phase I trial of temozolomide (NSC 362856) in patients with advanced cancer. Clin Cancer Res: an official journal of the American Association for Cancer Research. 1997;3(7):1093-100.

96. Middleton MR, Grob JJ, Aaronson N, Fierlbeck G,

Tilgen W, Seiter S, et al. Randomized phase III study of temozolomide versus dacarbazine in the treatment of patients with advanced metastatic malignant melanoma. J Clin Oncol Off J Am Soc Clin Oncol. 2000;18(1):158-66.

97. Kulke MH, Hornick JL, Frauenhoffer C, Hooshmand S, Ryan DP, Enzinger PC, et al. O6-methylguanine DNA methyltransferase deficiency and response to temozolomide-based therapy in patients with neuroendocrine tumors. Clin Cancer Res: an official journal of the American Association for Cancer Research. 2009;15(1):338-45. https://doi.org/10.1158/10780432.CCR-08-1476.

98. Hadoux J, Favier J, Scoazec JY, Leboulleux S, Al Ghuzlan A, Caramella C, et al. SDHB mutations are associated with response to temozolomide in patients with metastatic pheochromocytoma or paraganglioma. Int J Cancer. 2014;135(11):2711-20. https://doi.org/10.1002/ijc.28913.

99. Bravo EL, Kalmadi SR, Gill I. Clinical utility of temozolomide in the treatment of malignant paraganglioma: a preliminary report. Hormone Metab Res=Hormon- und Stoffwechselforschung=Hormones et metabolisme. 2009;41(9):703-6. https://doi.org/ 10.1055/s-0029-1,224,135.

100. Tena I, Gupta G, Tajahuerce M, Benavent M, Cifrián $\mathrm{M}$, Falcon A, et al. Successful second-line metronomic temozolomide in metastatic paraganglioma: case reports and review of the literature. Clin Med Insights Oncol. 2018;12:1179554918763367. https://doi. org/10.1177/1179554918763367.

101. Farago AF, Yeap BY, Stanzione M, Hung YP, Heist RS, Marcoux JP, et al. Combination olaparib and temozolomide in relapsed small-cell lung cancer. Cancer Discov. 2019;9(10):1372-87. https://doi.org/10. 1158/2159-8290.CD-19-0582.

\section{Publisher's note}

Springer Nature remains neutral with regard to jurisdictional claims in published maps and institutional affiliations. 